\title{
The Relationship Between EBV Virus and Breast Cancer in Khuzestan Province of Iran
}

\author{
Zahra Saeedi', Faranak Hadi ${ }^{*}$, Seyed Hesamaldin Hejazi ${ }^{1}$, Zahra Salahshournia ${ }^{1}$ \\ ${ }^{1}$ Department of Biology, Faculty of Science, Lorestan University, Khorramabad, Iran \\ Corresponding Author: Faranak Hadi, Assistant Professor, Department of Biology, Faculty of Science, Lorestan University, \\ Khorramabad, Iran. Tel: +98-9163613623, Email: hadi.f@lu.ac.ir
}

Received Dcember 25, 2017; Revised March 2, 2018; Accepted March 10, 2018; Online Published March 30, 2018

\begin{abstract}
Introduction: Many study results have suggested that infection by the Epstein-Barr virus is a possible agent of human breast cancer. But the role of Epstein-Barr virus in breast cancer is still controversial.

Materials and Methods: Paraffin embedded formalin fixed specimens were prepared from 40 breast and 40 healthy tissues in Khuzestan province of Iran. After DNA extraction, the purity of all DNA samples was evaluated by amplification of constitutive beta-actin gene. Then the presence of EBV gene in DNA extraction with appropriate purity was assessed by polymerase chain reaction (PCR) using virus specific primers.

Results: only 2 out 39 cases of tumor (5.12\%) and none of the 37 healthy samples were positive for the presence of Epstein-Barr virus. Statistically, Cramer's index for EBV infection was 0.160 in cancer samples.

Conclusions: Our results indicated that there is no significant relationship between breast cancer and Epstein-Barr virus. Further investigation on more patients needed to determine the exact relationship between EBV and breast cancer in this province.

Keywords: Breast Cancer, Epstein-Barr Virus, Polymerase Chain Reaction

Citation: Saeedi Z, Hadi F, Hejazi SH, Salahshournia Z. The relationship between EBV virus and breast cancer in Khuzestan province of Iran. J Appl Biotechnol Rep. 2018;5(1):37-41. doi:10.29252/jabr.01.01.07.
\end{abstract}

\section{Introduction}

Breast cancer is the most frequently diagnosed cancer among women worldwide. ${ }^{1}$ The incidence of breast cancer in Iran is about 20 new cases per 100000 women-years. ${ }^{2}$ This cancer often leads to complete removal of breast tissue, chemotherapy, radiotherapy and hormonotherapy. ${ }^{3}$ Several internal and external factors contribute to the development of this cancer. Internal factors such as age, hormonal effects, lifestyle, obesity, alcohol consumption, smoking, gender, anxiety and stress, genetic predisposition (mutation in BRCA1, 2 and other genes) and family history of breast cancer. ${ }^{4,5}$ Exogenous factors include infection with oncogenic viruses such as mouse mammary tumor virus (MMTV), human papilloma virus (HPV) and Epstein-Barr virus (EBV). Oncogenic viruses are contributing to $20 \%$ of human cancers. ${ }^{6} \mathrm{EBV}$ is a human gamma-1 herpes virus which has a double-stranded DNA genome comprised of approximately 170-kilobases that codes more of 85 genes, belonging to the $\mathrm{c}$ herpes virus family. ${ }^{7,8} \mathrm{EBV}$ is mostly transmitted from the host to another host via saliva and infects over $90 \%$ of the world population and remains in the body for life. ${ }^{9}$ Breast epithelial cells can be infected with EBV by cell to cell contact. ${ }^{10}$ This virus is accepted as a major contributor to $20 \%$ Burkitt lymphoma, 50\% Hodgkin's lymphoma, 10\% stomach carcinomas and almost all endemic nasopharyngeal carcinoma. ${ }^{11}$
The first step for the demonstration of the association between cancer and viruses is to detect the virus in the affected tissues. ${ }^{12}$ The primary evidence of the possibility of EBV involvement in breast cancer was reported by Lobreque et al who observed EBV sequencing in $21 \%$ of breast cancer specimens. ${ }^{13}$ However, in other studies, there were different results with the probability of correlation between 0 and $100 \%{ }^{13-18}$ EBV was identified in non-cancer breast controls in only 2 of 13 studies. ${ }^{19}$ EBV can contribute to the development of breast cancers directly through several mechanisms such as activation of HER2/HER3 signaling cascades. HER2 and HER 3 are 2 of the cellular oncogenes associated with breast cancer. $^{20}$

EBV has an indirect role in breast cancer development by interfering with the immune response to HPV-transformed cells via the expression viral BCRF1 gene. This collaboration between EBV and HPV may increase their oncogenic potential. $^{21}$

Not only the association of the EBV with breast cancer is important but also understanding of the cause of breast cancer for the early diagnosis, prevention, and treatment of breast cancer is necessary]. ${ }^{22}$ The aim of this study was to investigate the relationship between Epstein-Barr virus and breast cancer in women with this cancer in Khuzestan province. 


\section{Materials and Methods}

Sampling

Formalin-fixed, paraffin-embedded tissue blocks from 40 breast carcinoma and 40 healthy tissues were retrieved from pathological laboratories in Khuzestan province. These patients divided into 3 age groups of 23-38, 39-54 and 5470 years old. The age group of $39-54$ years old showed the highest incidence of breast cancer in this province.

\section{DNA Extraction}

For DNA Extraction, one $5 \mu \mathrm{m}$ paraffin section from each case was dewaxed in $1000 \mu \mathrm{L}$ xylene (Merk, Company Germen) for 15 minutes at $45^{\circ} \mathrm{C}$, rehydrated through graded ethanol (5 minutes each in $100 \%, 80 \%, 60 \%, 40 \%$ and $20 \%$ ethanol) and air dried. Tissues were incubated in $500 \mu \mathrm{L}$ lysis buffer (1.21 g/L Tris, $32.4 \mathrm{~g} / \mathrm{L} \mathrm{NaCl,} 0.75 \mathrm{~g} / \mathrm{L}$ EDTA, $7 \mathrm{~g} / \mathrm{L}$ SDS) and $20-40 \mu \mathrm{L}$ proteinase $\mathrm{K}$ overnight at $55^{\circ} \mathrm{C}$, followed by heat inactivation of proteinase K. DNA was Precipitate and dissolve in ddH2O.

\section{PCR for Amplification of Beta-Actin and EBV}

To investigate the quality of DNA extracted from cancerous and healthy tissues, about $1 \mu \mathrm{L}$ of DNA is deposited in a nanodrop, and the amount of DNA absorption was measured at 280 to $260 \mathrm{UV}$. Suitability of DNA for PCR was analyzed by amplifying the housekeeping beta-actin gene. A 161 base pair fragment of beta-actin gene was reproduced using PCR by following primers: 5'AGACGCAGGATGGCATGGG3' and 5'GAGACCTTAAACACCCCAGCC3'. Then PCR was performed for detection EBV sequencein DNA extraction using two specific primers 5'TCTTGAGGATCCGCTAGGATA3' and 5'ACCGTGGTTCTGGACTATCTGGAT3'.

The PCR program consisted of initial denaturing at $95^{\circ} \mathrm{C}$ for 5 minutes, followed by 30 cycles, including $94^{\circ} \mathrm{C}$ for 45 seconds, annealing at $61^{\circ} \mathrm{C}$ and $55^{\circ} \mathrm{C}$ respectively, for beta actin and EBV gene, for 45 seconds and extension at $72^{\circ} \mathrm{C}$ for 45 seconds and a final extension $72^{\circ} \mathrm{C}$ for 10 minutes. The reaction volume was $20 \mu \mathrm{L}$ containing $10 \mu \mathrm{L}$ master mix, 20 ng DNA, 1 pmol primer, PCR products were separated on $1.5 \%$ agarose gel. No-template control, as a negative control, was included in all PCR.

\section{Statistical Analysis}

To perform the analysis, Cramer test and SPSS 16 software were used. Statistical significance was a $P$ value of less than 0.05 .

\section{Ethical Considerations}

All patients and healthy donors provided their written informed constantly to take part in this study, and the study was approved by the Ethics Committee of Lorestan University.

\section{Results}

Evaluation of Concentration and Purity of DNA

DNA extraction of cancerous and healthy samples that measured by UV absorption was used for amplification of

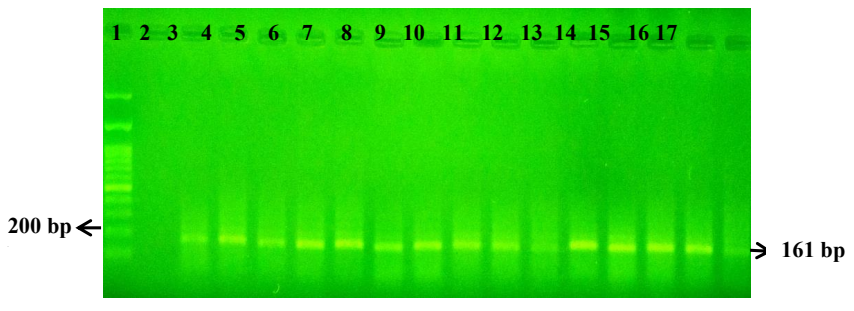

Figure 1. PCR Amplification of the Beta-Actin Gene in Healthy and Cancerous Tissues With the Specific Primers. Line 1, DNA Ladder (Fermentas); Line 2, negative control (ddH2O); Lines 3-10, healthy samples; Lines 10-17, tumor samples.

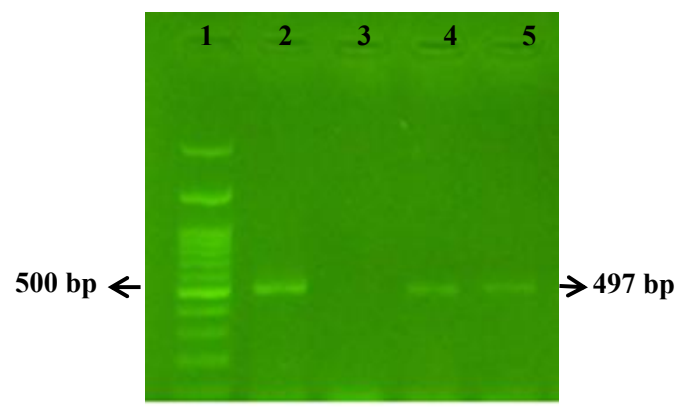

Figure 1. PCR Amplification of the Beta-Actin Gene in Healthy and Cancerous Tissues With the Specific Primers. Line 1, DNA Ladder (Fermentas); Line 2, negative control (ddH2O); Lines 3-10, healthy samples; Lines 10-17, tumor samples.

constitutive beta actin gene. Results indicated that DNA extraction from 39 of the tumor samples and 37 of the healthy samples had acceptable quality and the band with a size of 161 bp was observed (Figure 1).

Then, DNA Extraction from tumor and healthy samples were subjected to amplify EBV- DNA by specific primers; healthy samples did not show the EBV gene present, two out of the 39 breast cancer cases $(5.12 \%)$ were diagnostically positive for EBV (Figure 2).

\section{Statistical Analyses}

According to statistical analysis, the correlation coefficient of Cramer calculated as 0.160 , and the criterion value of the decision is greater than 0.05 . Therefore, the assumption was accepted. There is no meaningful relationship between breast cancer and Epstein-Barr virus in patients with this cancer in Khuzestan province.

\section{Discussion}

Breast cancer is the second leading cause of cancer death among woman and almost one in eight women in the United States will be diagnosed with breast cancer in her lifetime. Many studies have been conducted to identify the risk factors for this cancer, But known risk factors for less than half of all cases are justifiable, and the known molecular mechanisms of breast cancer are very rare. ${ }^{17,23}$ The involvement of various viruses in human breast cancer has been widely studied, and very variable results have been reported, 
some evidence agrees or disagrees with this, so the issue is controversial. ${ }^{12}$ A possible explanation for the controversial results in correlation between EBV virus and breast cancer may result in the geographical variation in the incidence of EBV infections, for example, the primary infection with this virus in developing countries, especially in the Asian regions usually happens in the first decade of life, while in the western countries and developed regions primary infection by EBV occurs mainly in adolescence or adulthood. ${ }^{24,25}$ Moreover, different methods that used different EBV derived proteins or nucleic acids targeted for the viral genome detection are different. The subset of breast cancer studied, using varied techniques like polymerase chain reaction (PCR), laser capture microdissection (LCM), IHC, ISH, and Southern Blot for EBV detection. Hence, it is the main reasons for the conflicting results. ${ }^{26-28}$

Studies PCR as a highly sensitive and specific technique to detect EBV-DNA in breast cancer, leading to different results and making it difficult to determine whether EBV virus is correlated with breast cancer. In the present study, which was performed by PCR analysis, only 2 cases out of the 40 tumor samples (5\%) were positive and none of 40 normal tissues, showed DNA-EBV, These results indicated that Epstein-Barr virus does not play a significant role in breast cancer in women from Khuzestan. In other studies, PCR and real-time PCR were used on 18 breast cancer tissues from Iran and EBV virus was not found. Hence, the EBV does not play a significant role in this disease in Iran. ${ }^{29}$ The study by Morales-Sánchez et al using PCR technique to test whether EBV has such an association with breast cancer indicated that there is no significant relationship between EBV and Breast cancer. ${ }^{30}$ Perrigoue et al applied RT- PCR and ISH on detecting the number of viral DNA molecules in normal and tumor biopsies from 45 cases and reported no significant association between EBV and breast cancer. ${ }^{31}$ Eghbali et al tested a total of 24 carcinomas and 24 fibroadenomas paraffin embedded tumor tissue by PCR. They reported EBV infection in $16.6 \%$ of carcinoma and $4.1 \%$ of fibroadenoma samples, but this infection rate is statistically insignificant. ${ }^{32}$ Kadivar et al assessed 100 breast cancer and normal samples by PCR and EBNA-1 and LMP-1 were not detected in all of them. ${ }^{33}$

Different studies proposed the EBV virus may associate with breast cancer. ${ }^{34,35}$ They found material related to viruses in breast cancer. Herrmann and Niedobitek looked for EBV-DNA by PCR techniques, EBV encoded RNAs by in situ hybridization EBV and nuclear antigen by immunohistochemistry in 59 breast carcinoma biopsies. Only 4 out of 59 cases were positive for EBV-DNA, and other techniques ruled out the involvement of Epstein-Barr virus in the pathogenesis of breast carcinomas. ${ }^{36}$ Tsai and colleagues used PCR and Southern hybridization to detect six viruses in breast cancer tissues, and it was seen that human herpesvirus (HHV)-8 and EBV were associated with this cancer. ${ }^{37}$ In a study by Chu et al EBV-DNA detection was investigated by PCR using 48 samples of invasive breast cancer tissues, immunohistochemistry and in situ hybridization techniques and reported no significant correlation between this cancer and Epstein-Barr virus. ${ }^{38}$ Mazouni et al by using RT-PCR in 196 breast cancer specimens showed the presence of EBV in 65 out of 196 breast cancer. ${ }^{15}$ While some studies have shown that EBV may be present in breast cancer. Kazemi Aghdam et al studied 75 women with breast cancer and 75 cases with normal breast tissue by qualitative real-time PCR and $9.3 \%$ of tumor and $0 \%$ of normal tissues, the EBV-DNA was found. They suggested that EBV may have an etiologic role in breast cancer in Iran. ${ }^{39}$ Joshi et al applied Immunohistochemistry and commercial enzyme-linked Immunosorbent assay (ELISA) kit and showed EBNA-1 expression in a significant proportion of breast cancer tissues from rural India. These patients also have a higher immunological response against EBNA-1 33. Although Joshi et al in their review article did not defend that EBV has an etiologic role in breast cancer. ${ }^{12}$ Glenn et al conducted a study based on in situ PCR on 27 breast cancer specimens and 18 normal breast specimens from women who had breast reduction surgery. They detected that EBV sequences are present in many human breast cancers. ${ }^{40}$ Richardson et al by QPCR and determination of serum immunoglobulin level for EBV and CMV, showed a possible association between EBV and breast cancer. They according to other PCR studies on EBV and CMV and breast cancer proposed several possibilities: 1, molecular analysis has limitations and cannot confirm whether the viruses are associated with breast cancer; however, using ISH in addition to PCR may increase the sensitivity; 2, the virus may be absent after development of the tumor, causing inconsistent results; 3 , more viruses may be responsible for breast cancer development at a later stage; 4 , multiple virus infections may increase the occurrence of breast cancer; 5, none of CMV and EBV has a role in cancer development. ${ }^{41}$ Viruses such as HPV, HBV, and EBV cause genome instability and making the cell proliferation out of control. These can express oncogenes lead to inhibition of apoptosis and increase of cell immortalization. ${ }^{42-44}$

Finally, to establish whether a virus is linked to cancer, some effective vaccines and antivirals can be used. If eliminating virus infection and cancer happened, or vaccines even change the age-old pattern of cancer, we can say there is a correlation between virus and cancer. But, the problem is that the specific drug and vaccine just exist for a virus that established to cause a disease or cancer. ${ }^{45}$

\section{Conclusions}

Our results showed that there is no etiologic relationship between Epstein-Barr virus and breast cancer in the women examined in Khuzestan province, or at least, EBV is not a major cause of breast cancer in woman from this province. Further investigation on more patients and in other regions are needed to demonstrate the association of EBV infection with breast cancer.

Authors' Contributions

ZS contributed to sample preparation, carried out the experiments. $\mathrm{FH}$ helped to design, analyze, interpret the data and took the lead in writing the manuscript. SHH participated in study design, analysis, and interpretation of the result. ZS helped ZS to do experiment. FH and 
SHH supervised the project. All authors read and approved the final manuscript.

\section{Conflict of Interest Disclosures}

The authors declare they have no conflicts of interest.

\section{References}

1. Tarver T. Cancer Facts \& Figures 2012. American Cancer Society (ACS). J Consum Health Internet. 2012;16(3):366-367. doi:10.108 0/15398285.2012.701177.

2. Harirchi I, Ebrahimi M, Zamani N, Jarvandi S, Montazeri A. Breast cancer in Iran: a review of 903 case records. Public Health. 2000;114(2):143-145. doi:10.1038/sj.ph.1900623.

3. Heravi Karimovi M, Pourdehqan M, Jadid Milani M, Foroutan SK, Aieen F. Study of the effects of group counseling on quality of sexual life of patients with breast cancer under chemotherapy at Imam Khomeini Hospital. J Mazandaran Univ Med Sci. 2006;16(54):43-51.

4. Parkin DM. The global health burden of infection-associated cancers in the year 2002. Int J Cancer. 2006;118(12):3030-3044. doi:10.1002/ijc.21731.

5. Hoffman-Goetz L, Clarke JN. Quality of breast cancer sites on the World Wide Web. Can J Public Health. 2000;91(4):281-284.

6. Lawson JS, Heng B. Viruses and breast cancer. Cancers (Basel). 2010;2(2):752-772. doi:10.3390/cancers2020752.

7. Rickinson $A B$, Young LS, Rowe M. Influence of the Epstein-Barr virus nuclear antigen EBNA 2 on the growth phenotype of virustransformed B cells. J Virol. 1987;61(5):1310-1317.

8. Kieff E, Rickinson AB. Epstein-Barr virus and its replication. In: Knipe DM, Howley PM, eds. Fields Virology. Philadelphia: Lippincott Williams \& Wilkins; 2001;2575-2627.

9. Cohen Jl. Epstein-Barr virus infection. N Engl J Med. 2000;343(7):481-492. doi:10.1056/nejm200008173430707.

10. Speck P, Longnecker R. Infection of breast epithelial cells with Epstein-Barr virus via cell-to-cell contact. J Natl Cancer Inst. 2000;92(22):1849-1851.

11. Chabay P, Preciado MV. Epidemiology of Epstein-Barr virus-associated pediatric lymphomas from Argentina. Bol Med Hosp Infant Mex. 2016;73(1):47-54. doi:10.1016/j. bmhimx.2015.12.002.

12. Joshi D, Buehring GC. Are viruses associated with human breast cancer? Scrutinizing the molecular evidence. Breast Cancer Res Treat. 2012;135(1):1-15. doi:10.1007/s10549-011-1921-4.

13. Labrecque LG, Barnes DM, Fentiman IS, Griffin BE. Epstein-Barr virus in epithelial cell tumors: a breast cancer study. Cancer Res. 1995;55(1):39-45.

14. Chu JS, Chen CC, Chang KJ. In situ detection of Epstein-Barr virus in breast cancer. Cancer Lett. 1998;124(1):53-57.

15. Preciado MV, Chabay PA, De Matteo EN, et al. Epstein-Barr virus in breast carcinoma in Argentina. Arch Pathol Lab Med. 2005;129(3):377-381. doi:10.1043/1543-2165(2005)129<377:ev ibci>2.0.co;2.

16. Mazouni C, Fina F, Romain S, et al. Epstein-Barr virus as a marker of biological aggressiveness in breast cancer. Br J Cancer. 2011;104(2):332-337. doi:10.1038/sj.bjc.6606048.

17. Grinstein S, Preciado MV, Gattuso P, et al. Demonstration of Epstein-Barr virus in carcinomas of various sites. Cancer Res. 2002;62(17):4876-4878.

18. Gaffey MJ, Frierson HF Jr., Mills SE, et al. Medullary carcinoma of the breast. Identification of lymphocyte subpopulations and their significance. Mod Pathol. 1993;6(6):721-728.

19. Lawson JS, Salmons B, Glenn WK. Oncogenic Viruses and Breast Cancer: Mouse Mammary Tumor Virus (MMTV), Bovine Leukemia Virus (BLV), Human Papilloma Virus (HPV), and Epstein-Barr Virus (EBV). Front Oncol. 2018;8:1. doi:10.3389/fonc.2018.00001.

20. Hu H, Luo ML, Desmedt C, et al. Epstein-Barr Virus Infection of Mammary Epithelial Cells Promotes Malignant
Transformation. EBioMedicine. 2016;9:148-160. doi:10.1016/j. ebiom.2016.05.025.

21. Szostek S, Zawilinska B, Kopec J, Kosz-Vnenchak M. Herpesviruses as possible cofactors in HPV-16-related oncogenesis. Acta Biochim Pol.2009;56(2):337-342.

22. Mant C, Hodgson S, Hobday R, D'Arrigo C, Cason J. A viral aetiology for breast cancer: time to re-examine the postulate. Intervirology. 2004;47(1):2-13. doi:10.1159/000076636.

23. Hankinson SE, Colditz GA, Willett WC. Towards an integrated model for breast cancer etiology: the lifelong interplay of genes, lifestyle, and hormones. Breast Cancer Res. 2004;6(5):213-218. doi:10.1186/bcr921.

24. Zhou XG, Sandvej K, Li PJ, et al. Epstein--Barr virus gene polymorphisms in Chinese Hodgkin's disease cases and healthy donors: identification of three distinct virus variants. J Gen Virol. 2001;82(Pt 5):1157-1167. doi:10.1099/0022-1317-82-5-1157.

25. Sugano N, Chen W, Roberts ML, Cooper NR. Epstein-Barr virus binding to CD21 activates the initial viral promoter via NF-kappaB induction. J Exp Med. 1997;186(5):731-737.

26. Khan G, Philip PS, Al Ashari M, Houcinat Y, Daoud S. Localization of Epstein-Barr virus to infiltrating lymphocytes in breast carcinomas and not malignant cells. Exp Mol Pathol. 2011;91(1):466-470. doi:10.1016/j.yexmp.2011.04.018.

27. Khan G, Philip PS, Al Ashari M. Is Epstein-Barr virus associated with aggressive forms of breast cancer? Br J Cancer. 2011;104(8):13621363; author reply 1364. doi:10.1038/bjc.2011.99.

28. Glaser SL, Hsu JL, Gulley ML. Epstein-Barr virus and breast cancer: state of the evidence for viral carcinogenesis. Cancer Epidemiol Biomarkers Prev. 2004;13(5):688-697.

29. Fadavi P, Rostamian M, Arashkia A, Shafaghi B, MahmoudzadehNiknam H. Epstein-barr virus may not be associated with breast cancer in Iranian patients. Oncol Discov. 2013;1(1):3. doi:10.7243/2052-6199-1-3.

30. Morales-Sanchez A, Molina-Munoz T, Martinez-Lopez JL, et al. No association between Epstein-Barr Virus and Mouse Mammary Tumor Virus with breast cancer in Mexican women. Sci Rep. 2013;3:2970. doi:10.1038/srep02970.

31. Perrigoue JG, den Boon JA, Friedl A, Newton MA, Ahlquist P, Sugden B. Lack of association between EBV and breast carcinoma. Cancer Epidemiol Biomarkers Prev. 2005;14(4):809-814. doi:10.1158/1055-9965.epi-04-0763.

32. Eghbali M, Ghane M, Mirinargesi M, Zare Mehrjardi A. Detection of Epstein Barr Virus among Benign and Malignant Breast Tumors. Asian J Exp Biol Sci. 2012;5:365-371. doi:10.3923/ ajbs.2012.365.371.

33. Kadivar M, Monabati A, Joulaee A, Hosseini N. Epstein-Barr virus and breast cancer: lack of evidence for an association in Iranian women. Pathol Oncol Res. 2011;17(3):489-492. doi:10.1007/ s12253-010-9325-z.

34. Lawson JS, Gunzburg WH, Whitaker NJ. Viruses and human breast cancer. Future Microbiol. 2006;1(1):33-51. doi:10.2217/17460913.1.1.33.

35. Hsu CR, Lu TM, Chin LW, Yang CC. Possible DNA viral factors of human breast cancer. Cancers (Basel). 2010;2(2):498-512. doi:10.3390/cancers2020498.

36. Herrmann K, Niedobitek G. Lack of evidence for an association of Epstein-Barr virus infection with breast carcinoma. Breast Cancer Res. 2003;5(1):R13-17. doi:10.1186/bcr561.

37. Tsai JH, Tsai CH, Cheng MH, Lin SJ, Xu FL, Yang CC. Association of viral factors with non-familial breast cancer in Taiwan by comparison with non-cancerous, fibroadenoma, and thyroid tumor tissues. J Med Virol. 2005;75(2):276-281. doi:10.1002/ jmv.20267.

38. Chu PG, Chang KL, Chen YY, Chen WG, Weiss LM. No significant association of Epstein-Barr virus infection with invasive breast carcinoma. Am J Pathol. 2001;159(2):571-578. doi:10.1016/ s0002-9440(10)61728-2. 
39. Kazemi Aghdam M, Nadji SA, Khoddami M, Baghizadeh Dezfuli $\mathrm{H}$, Khademi Y. Epstein-Barr Virus and Breast Carcinoma in Iran. Jundishapur J Microbiol. 2017;10(10):e12800. doi:10.5812/ jjm.12800.

40. Glenn WK, Heng B, Delprado W, lacopetta B, Whitaker NJ, Lawson JS. Epstein-Barr virus, human papillomavirus and mouse mammary tumour virus as multiple viruses in breast cancer. PLoS One. 2012;7(11):e48788. doi:10.1371/journal.pone.0048788.

41. Richardson AK, Currie MJ, Robinson BA, et al. Cytomegalovirus and Epstein-Barr virus in breast cancer. PLoS One. 2015;10(2):e0118989. doi:10.1371/journal.pone.0118989.

42. Mouh FZ, Mzibri ME, Slaoui M, Amrani M. Recent Progress in
Triple Negative Breast Cancer Research. Asian Pac J Cancer Prev. 2016;17(4):1595-1608.

43. Moore PS, Chang Y. Common Commensal Cancer Viruses. PLoS Pathog. 2017;13(1):e1006078. doi:10.1371/journal. ppat. 1006078.

44. Masrour-Roudsari J, Ebrahimpour S. Causal role of infectious agents in cancer: An overview. Caspian J Intern Med. 2017;8(3):153-158. doi:10.22088/cjim.8.3.153.

45. Sixbey JW, Lemon SM, Pagano JS. A second site for Epstein-Barr virus shedding: the uterine cervix. Lancet. 1986;2(8516):11221124. 